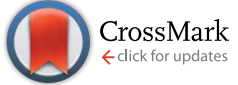

Cite this: J. Mater. Chem. A, 2015, 3, 23577

Received 1st September 2015 Accepted 13th October 2015

DOI: $10.1039 / c 5 t a 06939 d$

www.rsc.org/MaterialsA

\section{Triptycene based 1,2,3-triazole linked network polymers (TNPs): small gas storage and selective $\mathrm{CO}_{2}$ capture $\uparrow$}

\begin{abstract}
Snehasish Mondal and Neeladri Das*
Herein, facile synthesis and characterization of four triazole linked network polymers (TNPs) in high yields is described. These nitrogen rich polymers are derived using a "click" reaction between 2,6,14-triazido triptycene and various di- or triethynyl comonomers. The TNPs are microporous and exhibit high surface area $\left(S A_{B E T}\right.$ up to $1348 \mathrm{~m}^{2} \mathrm{~g}^{-1}$ ). Due to the incorporation of the 1,2,3-triazole motif (a $\mathrm{CO}_{2}$-philic moiety), the TNPs record moderate to high $\mathrm{CO}_{2}$ uptake (up to $4.45 \mathrm{mmol} \mathrm{g}^{-1}$ at $273 \mathrm{~K}$ and 1 bar). The TNPs also show very good $\mathrm{CO}_{2} / \mathrm{N}_{2}$ (up to 48 ) and $\mathrm{CO}_{2} / \mathrm{CH}_{4}$ (8-9) selectivity. While the highest storage capacity has been registered by TNP4 $\left(\mathrm{CO}_{2} 4.45 \mathrm{mmol} \mathrm{g}{ }^{-1}\right.$ at $273 \mathrm{~K}$ and 1 bar, $\mathrm{CH}_{4} 23.8 \mathrm{mg} \mathrm{g}^{-1}, \mathrm{H}_{2} 1.8$ wt\%), the highest $\mathrm{CO}_{2} / \mathrm{N}_{2}$ and $\mathrm{CO}_{2} / \mathrm{CH}_{4}$ selectivity is shown by TNP3 which contains additional nitrogen rich building blocks in the form of heteroaromatic pyrazine rings. These results suggest that TNPs are porous materials with potential practical application in gas storage and separation.
\end{abstract}

\section{Introduction}

Design and syntheses of porous materials have attracted considerable research attention over the past decade. ${ }^{\mathbf{1 - 4}}$ In recent years, research output in this direction has witnessed considerable growth. ${ }^{5-13}$ Depending on the pore size, porous materials may be classified as ultra-microporous ${ }^{14-16}$ microporous, ${ }^{12,13}$ mesoporous ${ }^{17-19}$ or macroporous. ${ }^{20,21}$ Among these, microporous materials have emerged as potential candidates for applications that include, but are not limited to, gas storage and separation. Microporous materials, such as zeolites ${ }^{22,23}$ and metal-organic frameworks (MOFs), ${ }^{1-5}$ contain metal atoms. Alternatively, microporous materials can also be designed in the form of metal-free organic polymers that are highly crosslinked. Acronyms such as COFs, CMPs, CTFs, EOFs, HCPs, MOPs, OCFs, PAFs, PIMs, POFs, POPs, PPFs, PPNs, etc. have been coined to describe metal-free porous organic polymers. ${ }^{6-13}$ In general, MOFs have limited industrial applications as porous materials because of the presence of relatively labile coordination bonds that lower their thermal stability. ${ }^{24}$ On the other hand, in microporous organic polymers (MOPs), light weight elements (such as $\mathrm{H}, \mathrm{C}, \mathrm{N}$, and $\mathrm{O}$ ) are interlinked via relatively stronger covalent bonds. Therefore these metal-free materials have lower mass densities and higher stabilities (chemical and thermal). In addition, MOPs can be easily tailored with respect to properties such as guest selectivity and pore properties, due

Department of Chemistry, Indian Institute of Technology Patna, Patna 800 013, Bihar, India.E-mail: neeladri@iitp.ac.in; neeladri2002@yahoo.co.in; Tel: +919631624708 $\uparrow$ Electronic supplementary information (ESI) available. See DOI: 10.1039/c5ta06939d to the availability of a plethora of multifunctional organic molecules that can serve as monomers towards the syntheses of MOPs.

In contemporary research dealing with the development of microporous materials, the design of MOPs for selective $\mathrm{CO}_{2}$ capture and sequestration has received special attention. ${ }^{\mathbf{2 4 - 4 6}}$ This has stemmed from environmental and energy concerns related to $\mathrm{CO}_{2}$, which is a major greenhouse gas. It is well known that thermal power plants emitting flue gas (containing approximately $15 \% \mathrm{CO}_{2}$ ) are a major contributor to anthropogenic $\mathrm{CO}_{2}$. Therefore, in order to contain global climate warming arising out of anthropogenic $\mathrm{CO}_{2}$ emissions, there is a pressing demand to develop novel materials that can efficiently and selectively adsorb large quantities of $\mathrm{CO}_{2}$ emitted from fossil-fuel fired power plants (classified as fixed-point $\mathrm{CO}_{2}$ emission sources). Also it is desirable to separate $\mathrm{CO}_{2}$ (present as an impurity) from natural gas that contains $80-95 \%$ methane. ${ }^{4748}$ This explains the growing research interest to design MOPs having practical applications such as selective capture and sequestration of $\mathrm{CO}_{2}$.

As far as the design of polymers for better $\mathrm{CO}_{2}$ adsorption and gas selectivity is concerned, it has been reported that incorporation of polar groups in the framework of porous organic polymers not only enhances carbon dioxide uptake but also improves its selectivity over methane and nitrogen. This enhancement in $\mathrm{CO}_{2}$ uptake is attributed to van der Waals interactions (quadrupole-dipole interactions and/or hydrogen bonding) between $\mathrm{CO}_{2}$ and the polar functional groups that are present in the backbone of MOPs. Additionally, polymeric networks synthesized from electron rich monomers may also exhibit higher $\mathrm{CO}_{2}$ uptake. This property is attributed to 
favorable Lewis acid-base interactions between the electron deficient carbon atom in $\mathrm{CO}_{2}$ and the relatively electron rich polymer. ${ }^{49,50}$

1,2,3-Triazole is a nitrogen rich motif and it can be easily incorporated in the polymer framework by reacting monomers with multiple azide and ethynyl functional groups. Nguyen and co-workers have described the synthesis of porous networks by covalently linking tetrahedral monomers using click chemistry. ${ }^{33}$ Triazole molecules (1,2,3- and 1,2,4-triazole) may be considered $\mathrm{CO}_{2}$-philic, considering the magnitude of their $\mathrm{CO}_{2}$ binding energies. ${ }^{51}$ It is therefore anticipated that polymers having these nitrogen rich moieties in their backbone may be potential candidates for efficient $\mathrm{CO}_{2}$ sorption and separation. Triptycene, on the other hand, is a robust and structurally rigid motif that has three dimensional orientation of three arene rings fused to a [2.2.2] bicyclooctatriene moiety. Triptycene based porous polymers have often exhibited good gas storage and separation properties. ${ }^{52-58}$ This is often attributed to the "internal molecular free volume (IFV)" that arises from the inefficient packing of rigid three dimensional units of triptycene present in the polymer backbone. ${ }^{52,55,57,58}$

With these premises in mind, we were interested in designing network polymers that would contain both the 1,2,3triazole motif (as polar groups) and triptycene motif (as a bulky rigid group). It is anticipated that such polymeric networks would be porous and simultaneously exhibit reasonably high uptake of $\mathrm{CO}_{2}$, primarily because of the $\mathrm{CO}_{2}$-philic nature of the polar 1,2,3-triazole moiety and the porosity arising from the inefficient packing of the triptycene units in the polymers.

Herein, we report the synthesis of a series of new triptycene based and 1,2,3-triazole linked network polymers (TNPs) using 2,6,14-triazidotriptycene and various $\mathrm{di}^{-}$and triethynyl substituted comonomers via a $\mathrm{Cu}(\mathrm{I}) \mathrm{OAc}$ catalyzed "click" reaction. Complete structural characterization of these polymers and their performance as materials for gas storage as well as selective gas uptake has been described elaborately. TNPs constructed from monomers with three ethynyl functional groups have a relatively higher surface area than TNPs derived from diethynyl comonomers. However, all TNPs exhibit microporosity (pore diameter $<2 \mathrm{~nm}$ ). Additionally, these microporous TNPs also demonstrate similar or even better carbon dioxide storage ability and selectivity than a wide range of previously reported MOPs.

\section{Experimental section}

\section{Materials and methods}

Triptycene, aromatic bromides and $\mathrm{Cu}(\mathrm{I}) \mathrm{OAc}$ were obtained from Sigma Aldrich and were utilized without further purification. 2,6,14-Triazidotriptycene was prepared from triptycene using a literature reported protocol. ${ }^{59}$ All the aromatic ethynyl compounds were synthesized from the corresponding aromatic bromides using the Sonogashira cross-coupling reaction. ${ }^{60}$ Chromatographic purifications were performed using silica gel (100-200 mesh). Solid-state ${ }^{13} \mathrm{C}$ cross-polarization magic angle spinning (CP-MAS) NMR spectra were obtained using a BRUKER $300 \mathrm{MHz}$ (H-1 frequency) NMR spectrometer at a mass rate of $8 \mathrm{kHz}$ and $\mathrm{CP}$ contact time of $2 \mathrm{~ms}$ with a delay time of $3 \mathrm{sec}$. FTIR analyses were performed using a Shimadzu IR Affinity-1 spectrometer. Elemental analyses were performed using a vario MICRO cube analyser. P-XRD data were recorded using a Rigaku TTRAX III X-ray diffractometer. Porosity analyses were performed using a Quantachrome Autosorb iQ ${ }_{2}$ Analyzer using UHP grade adsorbates. In a typical experiment, TNP (60-90 mg) was taken in a $9 \mathrm{~mm}$ large cell and attached to the degasser unit and degassed at $120{ }^{\circ} \mathrm{C}$ for $12-24 \mathrm{~h}$. The samples were refilled with helium and weighed carefully and then the cells were attached to the analyzer unit. The temperature was maintained using a KGW isotherm bath (provided by Quantachrome) filled with liquid $\mathrm{N}_{2}(77 \mathrm{~K})$, or a temperature controlled bath (298 K and $273 \mathrm{~K}$ ).

\section{Synthesis of TNP1}

A typical experiment for the syntheses of TNPs is described using TNP1 as a representative example. 2,6,14-Triazidotriptycene (189 mg, $0.5 \mathrm{mmol}$ ), 2,6,14-triethynyltriptycene (163 $\mathrm{mg}, 0.50 \mathrm{mmol}$ ) and $\mathrm{Cu}(\mathrm{I}) \mathrm{OAc}(4 \mathrm{mg}, 0.03 \mathrm{mmol}$ ) were taken in a Schlenk flask under an inert atmosphere. Degassed DMF $(30 \mathrm{~mL})$ was added to the flask with continuous stirring to dissolve the reactants. The flask (containing the reactant) was subsequently heated at $120^{\circ} \mathrm{C}$ with vigorous stirring. After a few minutes of stirring, the reaction mixture assumed the form of a light yellow gelatinous precipitate. The reaction mixture was allowed to stir for additional 24 hours with the resultant formation of a large amount of gelatinous precipitate. The reaction mixture was cooled to room temperature and filtered through a glass frit followed by washing with DMF, DMSO, acetone, THF and dichloromethane. The product thus obtained was dried under reduced pressure at $100{ }^{\circ} \mathrm{C}$ and crushed with a mortar and pestle to yield a brownish yellow powder.

Yield: 338 mg, 96\%; FT-IR (KBr): 3404, 1660, 1464, 1221, 1035 $\mathrm{cm}^{-1}$. Elemental analysis: calculated for $\mathrm{C}_{46} \mathrm{H}_{25} \mathrm{~N}_{9}$ : $\mathrm{C} 78.51, \mathrm{H}$ 3.58, N 17.91. Found: C 72.57, H 3.67, N 15.13.

\section{Synthesis of TNP2}

TNP2 has been prepared following a similar procedure to that described for TNP1 using 2,6,14-triazidotriptycene (189 mg, $0.5 \mathrm{mmol}$ ), 4,4'-diethynyl-biphenyl (152 mg, $0.75 \mathrm{mmol}$ ) and $\mathrm{Cu}(\mathrm{I}) \mathrm{OAc}$ (4 mg, $0.03 \mathrm{mmol}$ ). Unlike TNP1, a large amount of yellow precipitate was observed after 24 hours stirring at $120^{\circ} \mathrm{C}$. After drying at reduced pressure at $120^{\circ} \mathrm{C}$, the final product was obtained as a light yellow powder.

Yield: $300 \mathrm{mg}$, 88\%; FT-IR (KBr): 3400, 1606, 1477, 1226, $1038 \mathrm{~cm}^{-1}$. Elemental analysis: calculated for $\mathrm{C}_{44} \mathrm{H}_{26} \mathrm{~N}_{9}$ : C 77.63, H 3.85, N 18.52. Found: C 71.97, H 4.36, N 15.93.

\section{Synthesis of TNP3}

This polymer was synthesized using 2,6,14-triazidotriptycene (189 mg, $0.5 \mathrm{mmol}$ ), 2,6-diethynylpyrazine (96 mg, $0.75 \mathrm{mmol}$ ) and $\mathrm{Cu}(\mathrm{I}) \mathrm{OAc}$ ( $4 \mathrm{mg}, 0.03 \mathrm{mmol}$ ). Unlike other TNPs, formation of a light brown fluffy precipitate was observed within a few minutes of stirring at $120{ }^{\circ} \mathrm{C}$. After 24 hours of stirring, formation of a considerable amount of fluffy precipitate was 
observed. After drying at reduced pressure at $120{ }^{\circ} \mathrm{C}$, the final product was obtained as a light brown fluffy powder.

Yield: $242 \mathrm{mg}, 85 \%$; FT-IR (KBr): 1569, 1489, 1238, $1033 \mathrm{~cm}^{-1}$. Elemental analysis: calculated for $\mathrm{C}_{32} \mathrm{H}_{17} \mathrm{~N}_{12}$ : C 67.48, $\mathrm{H} 3.01, \mathrm{~N}$ 29.51. Found: C 62.36, H 3.61, N 25.93.

\section{Synthesis of TNP4}

This polymer was synthesized using 2,6,14-triazidotriptycene (189 mg, $0.5 \mathrm{mmol}$ ), 1,3,5-triethynylbenzene ( $75 \mathrm{mg}, 0.50 \mathrm{mmol}$ ) and $\mathrm{Cu}(\mathrm{I}) \mathrm{OAc}(4 \mathrm{mg}, 0.03 \mathrm{mmol})$. In this case, a large amount of dark yellow gelatinous precipitation was observed after stirring for 24 hours. After drying at reduced pressure at $120^{\circ} \mathrm{C}$, the final product was obtained as a dark brown solid. The solid product was then crushed in a mortar to yield the final product as a brownish yellow powder.

Yield: $259 \mathrm{mg}$, 98\%; FT-IR (KBr): 3391, 1614, 1486, 1226, $1046 \mathrm{~cm}^{-1}$. Elemental analysis: calculated for $\mathrm{C}_{32} \mathrm{H}_{17} \mathrm{~N}_{9}$ : C 72.86, H 3.25, N 23.90. Found: C 65.74, H 4.09, N 20.82.

\section{Results and discussion}

\section{Synthesis and characterization of TNPs}

The TNPs were synthesized utilizing the well-known $\mathrm{Cu}(\mathrm{I})$ catalyzed click reaction that is known to regioselectively yield the 1,4-disubstituted 1,2,3-triazole derivative. It is well documented in the literature that "standard" azide-alkyne click reactions, carried out in water or water/DMF mixture, utilize $\mathrm{Cu}(\mathrm{I})$ species generated in situ via reduction of $\mathrm{CuSO}_{4}$ with sodium ascorbate. However, in recent years, copper(I) acetate is being used as the source of $\mathrm{Cu}(\mathrm{I})$ instead of the $\mathrm{CuSO}_{4} /$ sodium ascorbate mixture, since the latter catalytic system either yields insoluble products or reactions are sluggish in nature. ${ }^{61}$ Chen and Guan reported click polymerization using CuOAc (source of $\mathrm{Cu}^{\mathrm{I}}$ ) in DMF (as a solvent). ${ }^{62}$ Based on this literature report, we have synthesized a series of 1,4-disubstituted 1,2,3-triazole bridged network polymers (TNPs) using 2,6,14-triazidotriptycene and various monomers containing multiple ethynyl functional groups as outlined in Scheme 1.

In a typical reaction for the synthesis of TNPs, 2,6,14-triazidotriptycene, ${ }^{59}$ the corresponding ethynyl monomer (di- or triethynyl) and $6 \mathrm{~mol} \%$ (with respect to 2,6,14-triazidotriptycene) $\mathrm{Cu}(\mathrm{I}) \mathrm{OAc}$ were dissolved in $30 \mathrm{~mL}$ of DMF and refluxed for 24 hours under a $\mathrm{N}_{2}$ atmosphere. In the case of TNP1 and TNP4 that utilized triethynyl monomers, gelatinous precipitation was observed after completion of the reaction. In this case, upon drying the precipitate under vacuum, the final product was obtained as a brownish yellow solid. FESEM images of the product obtained for TNP1 and TNP4 revealed an aggregated sheet-like structure. On the other hand, in the case of reactions leading to the formation of TNP2 and TNP3 (using diethynyl monomers in conjugation with 2,6,14-triazidotriptycene), the corresponding products precipitated as fluffy solids which were distinctly different from the gelatinous precipitates observed in the case of TNP1 and TNP4. As a consequence, for TNP2 and TNP3, the FESEM images revealed the presence of aggregated particles in their morphologies which was distinctly different from that observed in the case of TNP1 and TNP4 (Fig. 1). Wide-angle X-ray diffraction (WAXD) analyses of TNPs suggested that these polymeric materials were amorphous in nature due to the featureless broad nature of the diffraction pattern in each case (Fig. 1). This amorphous nature of the TNPs was due to the rapid and irreversible formation of the triazole linkage during polymerization. ${ }^{12 b}$

The TNPs thus obtained were structurally characterized using solid state ${ }^{13} \mathrm{C}$ (CP-MAS) NMR, and Fourier transform infrared (FTIR) spectroscopy. The ${ }^{13} \mathrm{C}$ CP-MAS spectrum of TNP4 has been shown as a representative example (Fig. 2). The peak centered at $53 \mathrm{ppm}$ corresponds to the bridgehead carbon of triptycene. The appearance of this peak is consistent with that of literature reported triptycene based monomer or polymers ${ }^{54-57,59}$ thereby confirming the successful incorporation of the triptycene motif in the polymer backbone. The peaks due to the phenyl ring carbons of the triptycene appear in the range of 120-150 ppm. The resonance signal centered at $168 \mathrm{ppm}$ is assigned to a carbon present in the 1,2,3-triazole motif, thereby confirming the formation of 1,2,3-triazole linkages via the click reaction. The ${ }^{13} \mathrm{C}$ CP-MAS spectra (Fig. S1 $\dagger$ ) of the other TNPs match well with those of TNP4, thereby supporting the formation of the desired polymers as shown in Scheme 1.

Polymerization has also been confirmed by FTIR spectroscopic data analysis (Fig. S2 $\dagger$ ). The FTIR spectrum of TNP2 is shown as a representative example in Fig. 3. The characteristic band of the azide functional group present in the triptycene monomer $\left(2096 \mathrm{~cm}^{-1}\right)$ is absent in TNP2. Simultaneously, a band due to the $\mathrm{C}-\mathrm{H}$ stretching vibration of terminal alkynes (3280 $\mathrm{cm}^{-1}$ ), observed in the corresponding diethynyl comonomer, is missing in the FTIR spectrum of TNP2. This strongly suggests the click polymerization reaction between monomers containing terminal azide and terminal alkyne groups.

\section{Porosity measurements and gas storage studies}

Porous properties of the TNPs were investigated by subjecting these polymers to $\mathrm{N}_{2}$ adsorption-desorption measurements at $77 \mathrm{~K}$. The isotherms are characterized by a steep increase in slope in the low relative pressure range $\left(P / P_{0}=0-0.1\right)$ and this implies uptake of large quantities of $\mathrm{N}_{2}$ gas. Additionally, the isotherms are reversible in nature. These characteristic features of the obtained adsorption-desorption isotherms (Fig. 4) suggest that these are type-I isotherms and the corresponding TNP polymers reported herein are microporous materials, as per IUPAC classifications. ${ }^{63}$ A gradual increase in $\mathrm{N}_{2}$ uptake in the relatively high pressure range $\left(P / P_{0}=0.1-0.9\right)$ was also observed in these isotherms. In the case of all TNPs, the adsorption and desorption branches of the hysteresis loop remain almost parallel over an appreciable range of $P / P_{0}$, thereby suggesting that these materials (TNP1-4) show type $\mathrm{H} 4$ adsorption-desorption hysteresis. According to IUPAC, "the type $\mathrm{H} 4$ loop appears to be associated with narrow slit-like pores, but in this case the type I isotherm character is indicative of microporosity". ${ }^{63}$

An additional feature observed in the isotherms of TNP2 and TNP3 is their steep rise while the relative pressure $\left(P / P_{0}\right)$ is 

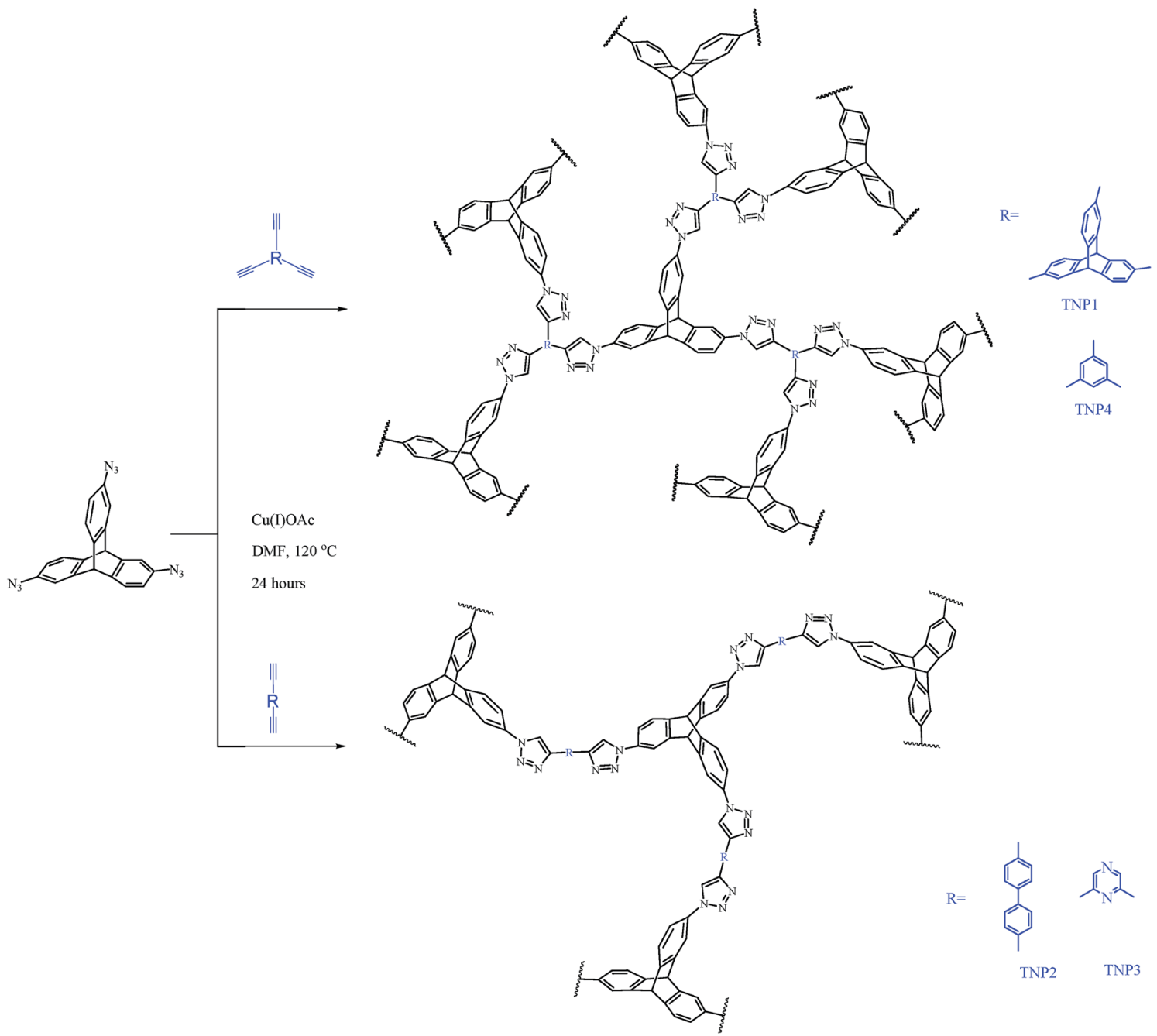

Scheme 1 Synthesis of TNP1-TNP4.

greater than 0.9, which is an indication of the presence of larger pores (macropores) and interparticle voids. ${ }^{24,64}$ Thus isotherms of TNP2 and TNP3 are distinctly different from those of TNP1 and TNP4. It may be recalled that in the FESEM micrographs, TNP2 and TNP3 exhibited particle-like nature having interparticle porosity, while TNP1 and TNP4 exhibit more aggregated plate-like morphologies suggesting that these have insignificant interparticle porosity. Thus conclusions drawn from the analysis of FESEM micrographs and adsorptiondesorption isotherms substantiate each other.
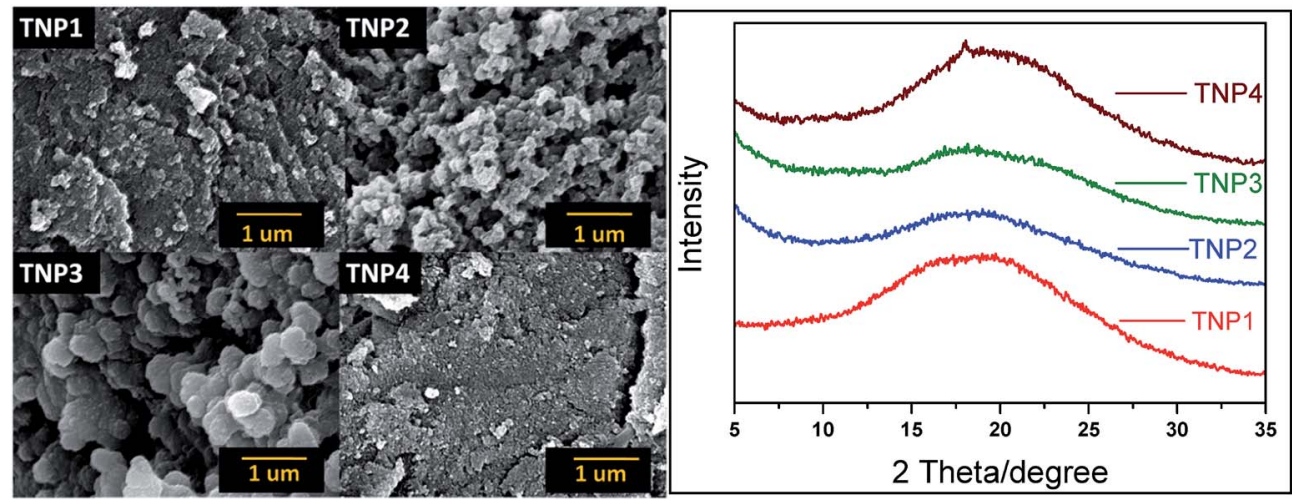

Fig. 1 FESEM micrograph of TNP1-TNP4 (left); WAXD pattern of TNP1-TNP4 recorded at ambient temperature at a scan rate of $3^{\circ}$ min ${ }^{-1}$ (right). 


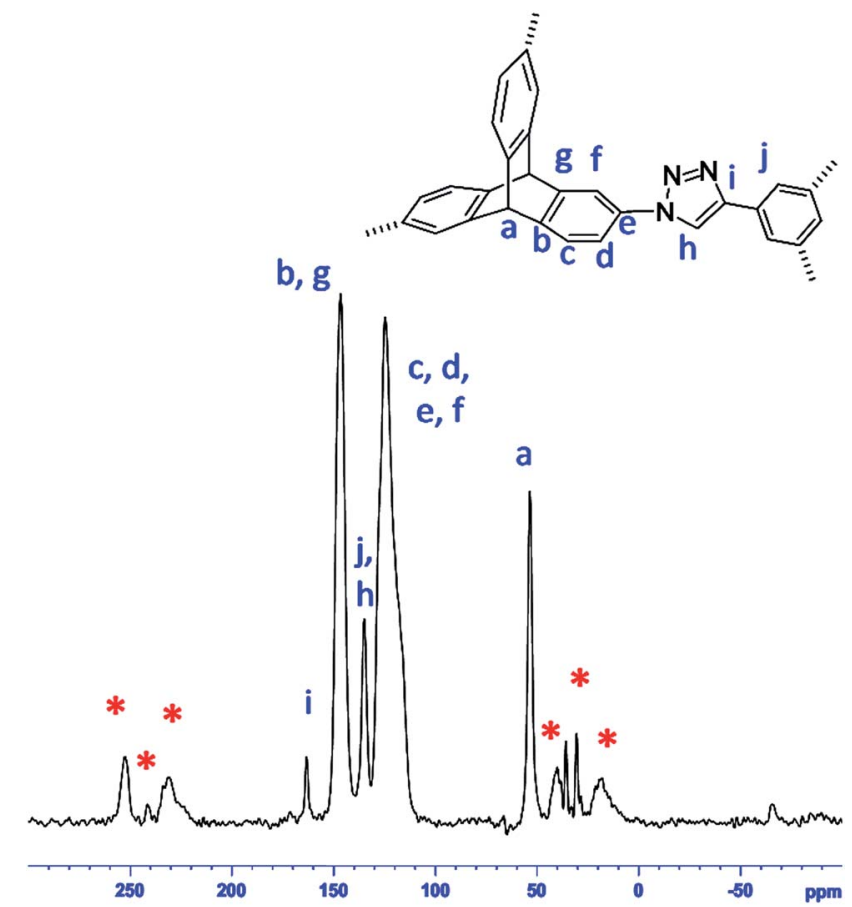

Fig. $2{ }^{13} \mathrm{C}$ CP-MAS NMR spectrum of TNP4, asterisks represent the spinning sideband.

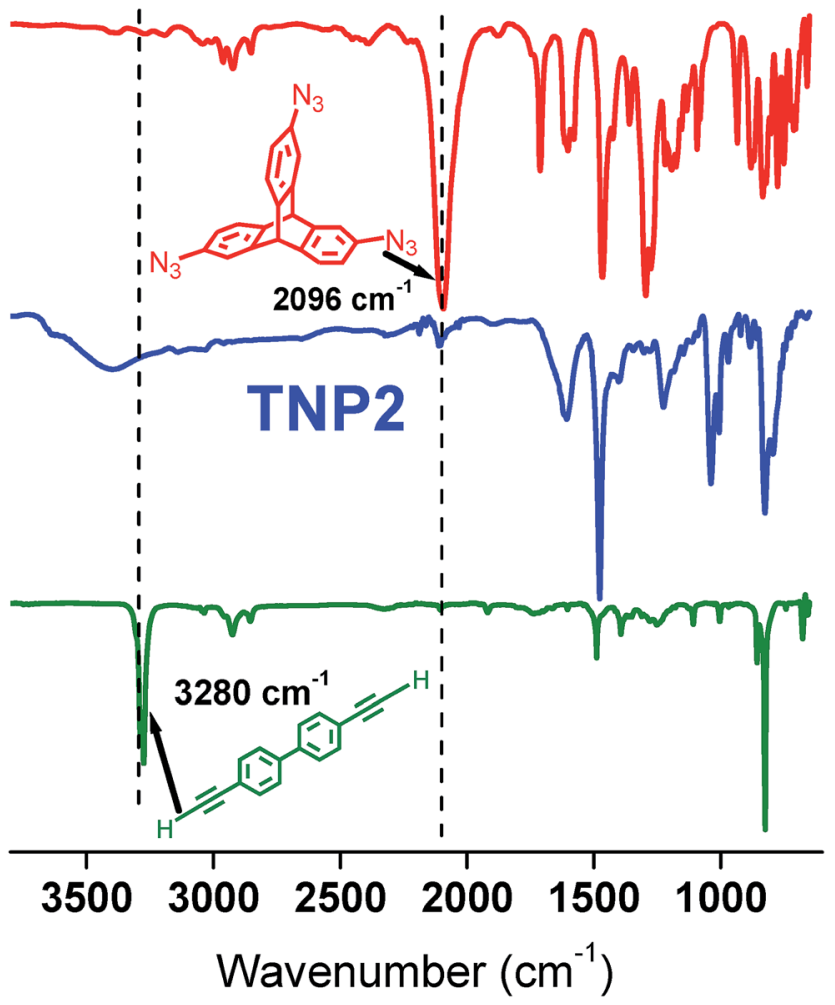

Fig. 3 FT-IR spectrum of 2,6,14-triazidotriptycene (top), TNP2 (middle), and 4,4'-diethynylbiphenyl (bottom).

DFT model based analysis results of pore size distributions (PSDs) of TNPs (calculated from $\mathrm{N}_{2}$ adsorption data at $77 \mathrm{~K}$ ) are depicted in Fig. 4b. In the case of TNP1 and TNP4 wherein both comonomers are trifunctional, the pores are smaller than $2 \mathrm{~nm}$. For these polymers, a narrow peak is observed in the ultramicroporous region (pore width $<0.7 \mathrm{~nm}$ ) at $0.59 \mathrm{~nm}$ and $0.57 \mathrm{~nm}$ respectively, thereby suggesting the presence of ultramicropores in these polymers. The PSD profiles of TNP2 and TNP3 also confirm the presence of micropores. Here a major peak is centered at $1.7 \mathrm{~nm}$ and $1.6 \mathrm{~nm}$ respectively for TNP2 and TNP3. The total pore volume of TNPs (calculated at $P / P_{0}=0.99$ ) is in the range of 0.53 to $0.66 \mathrm{~cm}^{3} \mathrm{~g}^{-1}$ (Table 1). In general, PSD is relatively narrow in the case of polymers (TNP1 and TNP4) that utilize both trifunctional monomers relative to polymers (TNP2 and TNP3) where one of the comonomers is bifunctional. These results clearly show that the pore size distribution of TNPs can be controlled by varying the number of reactive sites in the monomers. The microporous nature of TNPs is attributed to the presence of the rigid three dimensional triptycene motifs in the polymer backbone.

The surface areas (SAs) of TNPs have been obtained using the Brunauer-Emmett-Teller (BET) model within the pressure range $P / P_{0}=0.01$ to 0.1 (Fig. $\mathrm{S} 3 \dagger$ ). The $\mathrm{SA}_{\mathrm{BET}}$ obtained for TNP1, TNP2, TNP3 and TNP4 are $1090 \mathrm{~m}^{2} \mathrm{~g}^{-1}, 460 \mathrm{~m}^{2} \mathrm{~g}^{-1}, 745 \mathrm{~m}^{2} \mathrm{~g}^{-1}$ and $1348 \mathrm{~m}^{2} \mathrm{~g}^{-1}$ respectively. The corresponding Langmuir surface areas are $1475 \mathrm{~m}^{2} \mathrm{~g}^{-1}, 756 \mathrm{~m}^{2} \mathrm{~g}^{-1}, 1006 \mathrm{~m}^{2} \mathrm{~g}^{-1}$ and $1723 \mathrm{~m}^{2} \mathrm{~g}^{-1}$ respectively (Table 1 and Fig. S4 $\dagger$ ). Polymers TNP1 and TNP4 synthesized from triethynyl comonomers exhibit higher surface areas relative to the other two polymers (TNP2 and TNP3) where a diethynyl comonomer has been utilized for polymerization. This difference in the surface area of network polymers (TNP1 and TNP4) resulting from triethynyl monomers relative to polymers (TNP2 and TNP3) derived from disubstituted monomers is attributed to the higher extent of crosslinking as well as difference in the geometry of the comonomers. Irrespective of the nature of ethnyl monomer used in conjugation with 2,6,14-triazidotriptycene, the resulting TNPs are significantly porous and their corresponding surface areas $\left(\mathrm{SA}_{\mathrm{BET}}\right)$ are comparable to or better than those of a wide variety of microporous polymers reported in the literature such as mPAF (948-1314 $\left.\mathrm{m}^{2} \mathrm{~g}^{-1}\right),{ }^{27}$ benzimidazole-linked polymers (BILPs, 599-1306 m $\mathrm{g}^{-1}$ ), ${ }^{25,65,66}$ imine-linked PPFs (419-1740 $\mathrm{m}^{2}$ $\left.\mathrm{g}^{-1}\right),{ }^{24}$ nitrogen-doped microporous carbons $\left(263-744 \mathrm{~m}^{2} \mathrm{~g}^{-1}\right),{ }^{29}$ imine-linked POFs $\left(466-1521 \mathrm{~m}^{2} \mathrm{~g}^{-1}\right),^{31}$ nanoporous azo-linked polymers (ALPs, 862-1235 $\mathrm{m}^{2} \mathrm{~g}^{-1}$ ), ${ }^{32}$ "click-based" POPs (1090$\left.1440 \mathrm{~m}^{2} \mathrm{~g}^{-1}\right)^{33}$ and triptycene-based microporous polymers such as benzimidazole networks $\left(600 \mathrm{~m}^{2} \mathrm{~g}^{-1}\right),{ }^{56}$ porous polymers derived from Tröger's base (TB-MOP, $\left.694 \mathrm{~m}^{2} \mathrm{~g}^{-1}\right){ }^{58}$ and microporous polyimides (STPIs, 4-541 $\mathrm{m}^{2} \mathrm{~g}^{-1}$ ). ${ }^{54}$ The surface areas and pore properties are summarized in Table 1.

Considering the microporous nature of TNPs and the presence of nitrogen-rich 1,2,3-triazole moieties in the polymer framework, we were interested to investigate the potential of TNPs as porous materials for gas storage applications. It has been reported in the literature that nitrogen enriched microporous organic polymers perform well as materials for storage of small gas molecules in general and particularly $\mathrm{CO}_{2}$. Therefore to assess the performance of TNPs in selective gas storage materials, adsorption isotherms for $\mathrm{CH}_{4}, \mathrm{CO}_{2}$, and $\mathrm{H}_{2}$ were collected under different conditions. 

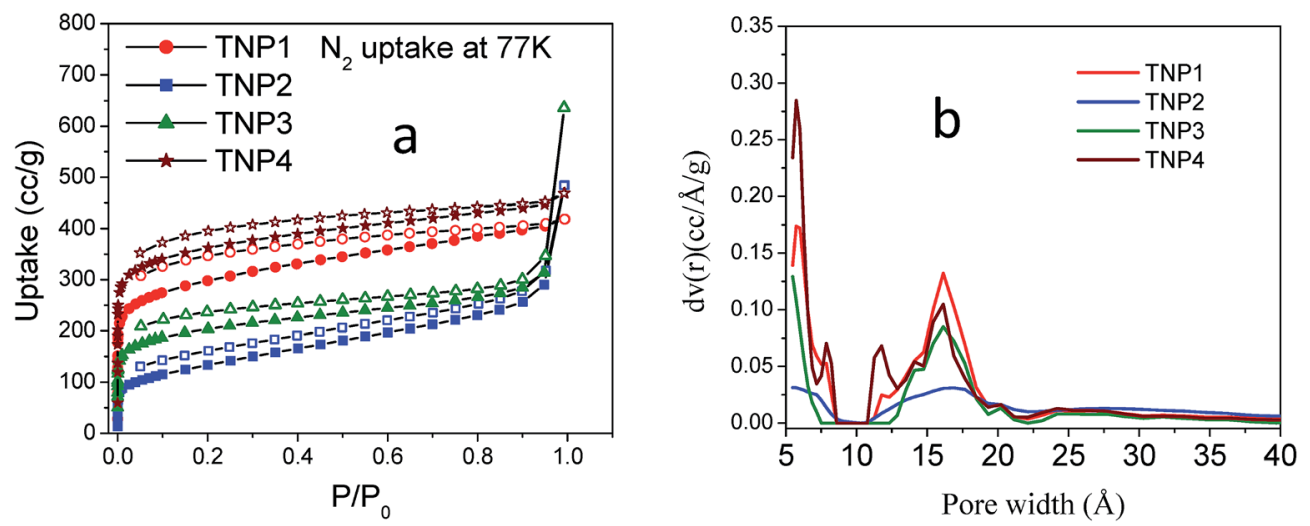

Fig. $4 \quad N_{2}$ adsorption isotherm of TNP1-TNP4 at $77 \mathrm{~K}(\mathrm{a})$; pore size distribution of TNP1-TNP4 (b).

The $\mathrm{CO}_{2}$ sorption isotherms of TNPs were collected at 273 and $298 \mathrm{~K}$ and pressures up to 1 bar. The corresponding $\mathrm{CO}_{2}$ isotherms register a steep rise in the initial low pressure region and are completely reversible in the entire region due to the absence of any significant adsorption-desorption hysteresis [Fig. 5a (273 K) and Fig. S5† (298 K)]. The reversibility suggests that interactions between TNPs and $\mathrm{CO}_{2}$ are weak to the extent of regeneration of the polymers without application of heat. ${ }^{32} \mathrm{As}$ observed in the case of $\mathrm{N}_{2}$ sorption analysis, TNPs (1 and 4) derived from triethynyl comonomers show higher uptake of $\mathrm{CO}_{2}$ relative to TNPs ( 2 and 3 ) derived from diethynyl comonomers. At $273 \mathrm{~K}$ and 1.0 bar, TNP4 demonstrates the highest $\mathrm{CO}_{2}$ uptake of $196 \mathrm{mg} \mathrm{g}^{-1}\left(4.45 \mathrm{mmol} \mathrm{g}^{-1}\right)$, while TNP2 shows the lowest value of $\mathrm{CO}_{2}$ uptake at $70 \mathrm{mg} \mathrm{g}^{-1}\left(1.59 \mathrm{mmol} \mathrm{g}^{-1}\right)$. Importantly, the magnitude of $\mathrm{CO}_{2}$ uptake by these TNPs is comparable to or better than those of various literature reported COFs. For example, the uptake of TNP4 $\left(4.45 \mathrm{mmol} \mathrm{g}^{-1}\right.$ at 273 $\mathrm{K} / 1$ bar) exceeds this value for $-\mathrm{OH}$ functionalized POFs $\left(4.2 \mathrm{mmol} \mathrm{g}^{-1}\right),{ }^{67}$ imine linked ILP $\left(1.97 \mathrm{mmol} \mathrm{g}^{-1}\right),{ }^{29}$ BLP1 $\left(4.27 \mathrm{mmol} \mathrm{g}^{-1}\right),{ }^{65}$ and tetraphenyladamantane based PAN (3.36-4.0 mmol g $\left.{ }^{-1}\right) \cdot^{37}$ In general, the $\mathrm{CO}_{2}$ uptake values (1.59$4.45 \mathrm{mmol} \mathrm{g}^{-1}$ at $273 \mathrm{~K} / 1 \mathrm{bar}$ ) of TNPs are comparable with those of various microporous organic polymers such as triazine based TBILP (2.66-5.18 mmol g $\left.{ }^{-1}\right),{ }^{42}$ microporous covalent triazine polymers (MCTP, 3.65-4.64 $\mathrm{mmol} \mathrm{g}^{-1}$ ), ${ }^{40}$ and carbazolic porous organic frameworks (Cz-POFs, $1.75-4.77 \mathrm{mmol} \mathrm{g}^{-1}$ ). ${ }^{38}$ Furthermore, the $\mathrm{CO}_{2}$ uptake capacities of these TNPs are comparable to those of MOFs such as $\mathrm{Zn}_{2}\left(\mathrm{C}_{2} \mathrm{O}_{4}\right)\left(\mathrm{C}_{2} \mathrm{~N}_{4} \mathrm{H}_{3}\right)_{2} \cdot\left(\mathrm{H}_{2} \mathrm{O}\right)_{0.5}(4.35$ $\left.\mathrm{mmol} \mathrm{g}^{-1}\right)^{68}$ and amine-functionalized MOFs such as bio-MOF- $11\left(6.0 \mathrm{mmol} \mathrm{g}{ }^{-1}\right) \cdot{ }^{69}$ The observed substantial uptake of $\mathrm{CO}_{2}$ by these triptycene-based TNPs can be considered as a consequence of high internal molecular free volume (IMFV) due to the triptycene units and high nitrogen content due to the triazole motifs. Recently, theoretical studies have shown that 1,2,3-triazole molecules have a large $\mathrm{CO}_{2}$-binding energy (BE) $\left(20.0 \mathrm{~kJ} \mathrm{~mol}^{-1}\right)$ possibly due to the high affinity of triazole rings for $\mathrm{CO}_{2}$ via strong electrostatic interactions. ${ }^{51}$

To further understand the interaction of $\mathrm{CO}_{2}$ with TNPs, the isosteric heats of adsorption $\left(Q_{\mathrm{st}}\right)$ for $\mathrm{CO}_{2}$ in TNPs were estimated from the $\mathrm{CO}_{2}$ adsorption isotherms at 273 and $298 \mathrm{~K}$. The $Q_{\text {st }}$ values for $\mathrm{CO}_{2}$ at zero coverage (at the onset of adsorption) are in the range of $34.8-38.5 \mathrm{~kJ} \mathrm{~mol}^{-1}$. Strong interactions between $\mathrm{CO}_{2}$ and polar 1,2,3-triazole motifs as well as the narrow distribution in the microporous region may be the reason for the high $Q_{\text {st }}$ value observed in the low pressure region. The $Q_{\mathrm{st}}$ values $\left(34.8-38.5 \mathrm{~kJ} \mathrm{~mol}^{-1}\right)$ of TNPs are higher than those of a variety of previously reported porous organic polymers such as nanoporous azo-linked polymers (ALPs: 27.9$29.6 \mathrm{~kJ} \mathrm{~mol}^{-1}$ ), ${ }^{32}$ imine-linked porous polymer frameworks (PPFs: $21.8-29.2 \mathrm{~kJ} \mathrm{~mol}^{-1}$ ), ${ }^{24}$ benzimidazole-linked polymers (BLPs: 26.7-28.0. $\mathrm{kJ} \mathrm{mol}{ }^{-1}$ ), ${ }^{25,65,66}$ nitrogen-rich networks (PECONFs: 26-34 kJ mol $\left.{ }^{-1}\right)^{64}$ nitrogen-rich diaminotriazinebased polymers (APOPs, 26.6-33.3 $\mathrm{kJ} \mathrm{mol}^{-1}$ ), ${ }^{70}$ and carbazolic porous organic frameworks (Cz-POFs, $\left.24.8-27.8 \mathrm{~kJ} \mathrm{~mol}^{-1}\right) .^{38}$ However these values are slightly less than those of microporous covalent triazine polymers (MCTPs, $30.6-40 \mathrm{KJ} \mathrm{mol}^{-1}$ ). ${ }^{40}$

In addition to $\mathrm{CO}_{2}$, TNPs were also investigated as materials for the sorption of other gases such as $\mathrm{H}_{2}$ and $\mathrm{CH}_{4}$ (Table 2).

Table 1 Reaction yield and pore properties of TNP1-TNP4

\begin{tabular}{|c|c|c|c|c|}
\hline Polymer & $\mathrm{SA}_{\mathrm{BET}}{ }^{a}\left(\mathrm{~m}^{2} \mathrm{~g}^{-1}\right)$ & $\mathrm{SA}_{\text {Lang }}^{b}\left(\mathrm{~m}^{2} \mathrm{~g}^{-1}\right)$ & $V_{\text {total }}{ }^{c}\left(\mathrm{~cm}^{3} \mathrm{~g}^{-1}\right)$ & Yield (\%) \\
\hline TNP1 & 1090 & 1475 & 0.58 & 96 \\
\hline TNP2 & 460 & 756 & 0.53 & 88 \\
\hline TNP4 & 1348 & 1723 & 0.66 & 98 \\
\hline
\end{tabular}

${ }^{a}$ Surface area calculated based on the BET model from the nitrogen adsorption isotherm $\left(P / P_{0}=0.01-0.1\right) .{ }^{b}$ Surface area calculated based on the Langmuir model from the nitrogen adsorption isotherms $\left(P / P_{0}=0.05-0.35\right) .{ }^{c}$ The total pore volume calculated at $P / P_{0}=0.99$. 

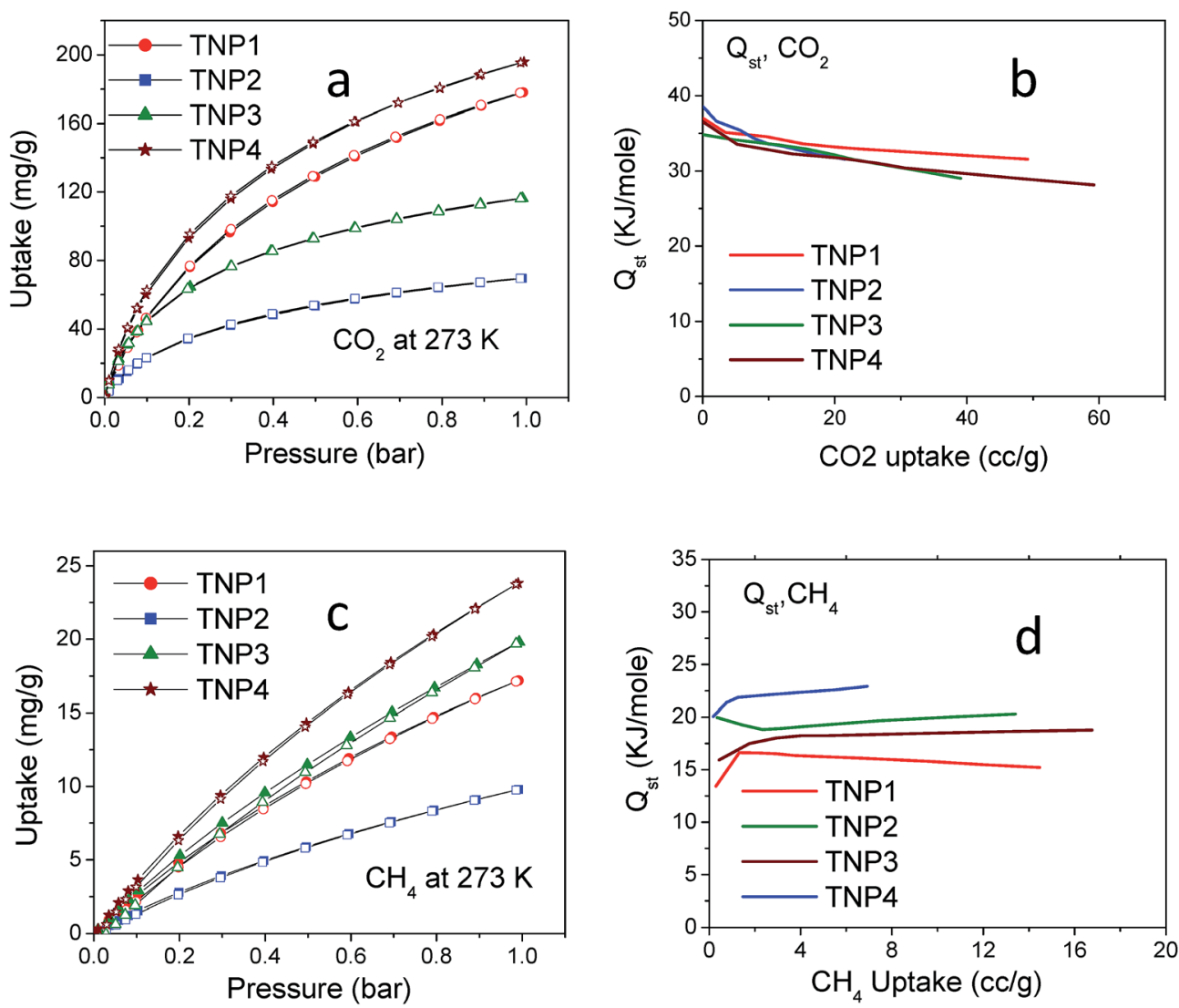

Fig. $5 \mathrm{CO}_{2}$ uptake isotherm of TNP1-TNP4 at $273 \mathrm{~K}(\mathrm{a})$, isosteric heat of adsorption $\left\{Q_{\mathrm{st}}\right\}$ of TNPs for $\mathrm{CO}_{2}$ (b), methane uptake isotherm of TNP1-TNP4 at $273 \mathrm{~K}$ (c) and $Q_{\text {st }}$ of TNPs for $\mathrm{CH}_{4}$ (d). Adsorption (filled) and desorption (empty).

$\mathrm{CH}_{4}$ gas isotherms of TNPs were collected at $273 \mathrm{~K}$ (Fig. 5c) and $298 \mathrm{~K}$ (Fig. S5 $\dagger$ ) up to 1 bar pressure. At $273 \mathrm{~K}$, TNP4 registers the highest methane uptake $\left(23.8 \mathrm{mg} \mathrm{g}^{-1}\right)$ while TNP2 records the lowest $\left(10.0 \mathrm{mg} \mathrm{g}^{-1}\right)$. Irrespective of the extent of methane sorption, all the isotherms are completely reversible. We have also calculated the isosteric heat of adsorption $\left(Q_{\mathrm{st}}\right)$ for methane in TNPs and values at zero coverage are found to be in the range of 13.2-20.0 $\mathrm{kJ} \mathrm{mol}^{-1}$. These magnitudes of $Q_{\mathrm{st}}$ are comparable with those of various hetero-functionalized porous organic polymers. . $4,25,27,32^{2}$

Similarly, $\mathrm{H}_{2}$ adsorption isotherms were collected at $77 \mathrm{~K}$ for TNPs (Fig. 6). The uptake capacity of $\mathrm{H}_{2}$ increases in the order of TNP2 < TNP3 < TNP1 < TNP4 which is consistent with the increasing order of surface area $\left(\mathrm{SA}_{\mathrm{BET}}\right)$. The $\mathrm{H}_{2}$ uptakes of TNPS are in the range of $0.8-1.8 \mathrm{wt} \%$ at $77 \mathrm{~K}$ and 1 bar, which is comparable with those of various organic porous polymers, such as nanoporous azo-linked polymers (ALPs, 1.39-2.19 $\mathrm{wt} \%)^{32}$ and benzimidazole-linked polymers (BILP1, $\left.1.9 \mathrm{wt} \%\right),{ }^{65}$ under identical experimental conditions.

\section{Gas selectivity}

After evaluation of the porosity and gas-uptake capacities of these TNPs, we were interested to study their ability to selectively capture $\mathrm{CO}_{2}$ over $\mathrm{CH}_{4}$ and $\mathrm{N}_{2}$. It is well known that in order to reduce environmental pollution due to $\mathrm{CO}_{2}$ (a greenhouse gas) present in flue gas $\left(\mathrm{N}_{2} / \mathrm{CO}_{2}: 85: 15\right)$, it is necessary to selectively capture $\mathrm{CO}_{2}$ over $\mathrm{N}_{2}$. Also it is well

Table $2 \mathrm{H}_{2}, \mathrm{CO}_{2}, \mathrm{CH}_{4}$, and $\mathrm{N}_{2}$ uptakes, isosteric heats of adsorption $\left(Q_{\mathrm{st}}\right)$ for TNPs, and selectivity for $\mathrm{CO}_{2} / \mathrm{N}_{2}$ and $\mathrm{CO}_{2} / \mathrm{CH}_{4}$

\begin{tabular}{|c|c|c|c|c|c|c|c|c|c|c|c|}
\hline \multirow[b]{2}{*}{ Polymer } & \multirow[b]{2}{*}{$\begin{array}{l}\mathrm{H}_{2} \text { at } \\
1 \text { bar }(77 \mathrm{~K})\left(\mathrm{mg} \mathrm{g}^{-1}\right)\end{array}$} & \multicolumn{3}{|c|}{$\mathrm{CO}_{2}$ at $1 \mathrm{bar}\left(\mathrm{mg} \mathrm{g}^{-1}\right)$} & \multicolumn{3}{|c|}{$\mathrm{CH}_{4}$ at $1 \mathrm{bar}\left(\mathrm{mg} \mathrm{g}^{-1}\right)$} & \multicolumn{2}{|c|}{$\begin{array}{l}\mathrm{N}_{2} \text { at } 1 \text { bar } \\
\left(\mathrm{mg} \mathrm{g}^{-1}\right)\end{array}$} & \multicolumn{2}{|l|}{ Selectivity } \\
\hline & & $273 \mathrm{~K}$ & $298 \mathrm{~K}$ & $Q_{\mathrm{st}}$ & $273 \mathrm{~K}$ & $298 \mathrm{~K}$ & $Q_{\text {st }}$ & $273 \mathrm{~K}$ & $298 \mathrm{~K}$ & $\begin{array}{l}\mathrm{CO}_{2} / \mathrm{N}_{2} 273 \\
\mathrm{~K}(298 \mathrm{~K}) \\
\end{array}$ & $\begin{array}{l}\mathrm{CO}_{2} / \mathrm{CH}_{4} 273 \\
\mathrm{~K}(298 \mathrm{~K})\end{array}$ \\
\hline TNP1 & 14 & 178 & 99 & 37.0 & 17.3 & 11.5 & 13.2 & 3.4 & 2.1 & $36(23)$ & $8(5)$ \\
\hline TNP2 & 8 & 70 & 43 & 38.5 & 10.0 & 5.2 & 20 & 2.3 & 1.1 & $40(23)$ & $8(5)$ \\
\hline
\end{tabular}




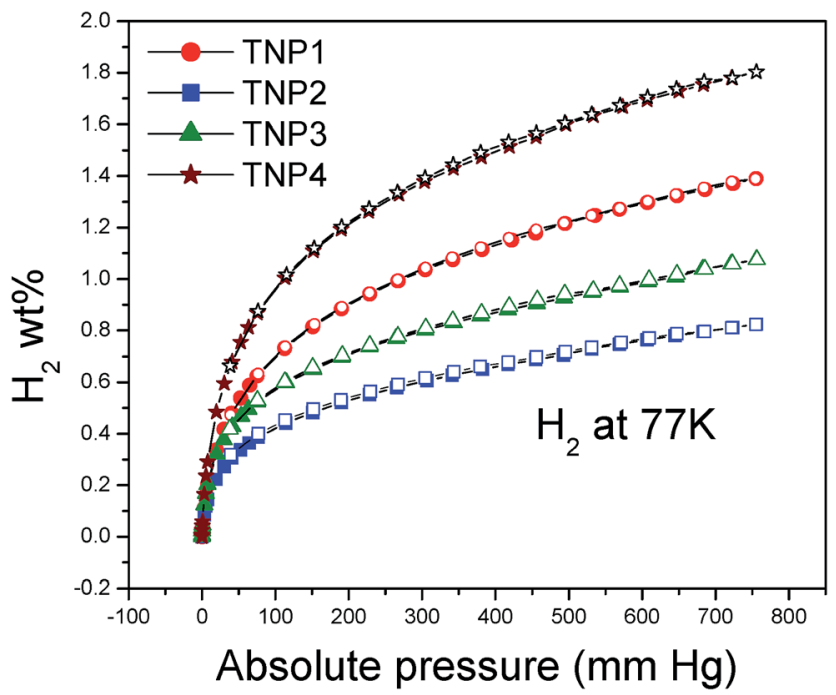

Fig. $6 \mathrm{H}_{2}$ uptake isotherms of TNP1-TNP4 at $77 \mathrm{~K}$. Adsorption (filled) and desorption (empty).

accepted that $\mathrm{CO}_{2}$ is a contaminant in natural gas $\left(\mathrm{CH}_{4} / \mathrm{CO}_{2}\right.$ : $95: 5)$ and it is necessary to selectively capture $\mathrm{CO}_{2}$ over methane in order to improve the quality of natural gas as a fuel and also control corrosion in pipelines due to $\mathrm{CO}_{2}$.
In order to access the performance of TNPs in $\mathrm{CO}_{2} / \mathrm{CH}_{4}$ and $\mathrm{CO}_{2} / \mathrm{N}_{2}$ gas selectivities, it is required to record the single component adsorption isotherms of these gases at $273 \mathrm{~K}$ (Fig. 7) and $298 \mathrm{~K}$ (Fig. S6†) up to 1 bar pressure. For a given TNP, an initial steeper rise in the $\mathrm{CO}_{2}$ adsorption isotherm in comparison to that in the case of the corresponding $\mathrm{N}_{2}$ or $\mathrm{CH}_{4}$ isotherm was anticipated, considering the higher $Q_{\text {st }}$ values of TNPs for $\mathrm{CO}_{2}$ in zero surface coverage (Table 2) due to the favorable interactions between $\mathrm{CO}_{2}$ and $\mathrm{N}_{2}$ centers present in the 1,2,3triazole moieties. It must be mentioned here that in flue gas, $\mathrm{CO}_{2}$ partial pressure is typically 0.15 bar at $273 \mathrm{~K} .{ }^{25}$ Thus for a given porous material, it is worth considering its relative uptake of gases $\left(\mathrm{CO}_{2} v s . \mathrm{N}_{2}\right.$ or $\left.\mathrm{CH}_{4}\right)$ at 0.15 bar while evaluating its performance in selective gas adsorption. In the case of TNPs, at 0.15 bar the adsorption isotherms indicate significantly higher $\mathrm{CO}_{2}$ uptake relative to $\mathrm{N}_{2}$ or $\mathrm{CH}_{4}$. Considering this fact, these TNPs can be considered as useful materials for selective $\mathrm{CO}_{2}$ gas adsorption applications under these conditions.

Subsequently, $\mathrm{CO}_{2} / \mathrm{N}_{2}$ and $\mathrm{CO}_{2} / \mathrm{CH}_{4}$ gas selectivity of these TNPs was estimated from the initial slope ratios using Henry's law constants for single-component adsorption isotherms (Fig. S7 and S8†). This method has been routinely used to study gas selectivity properties of a wide variety of organic and inorganic hybrid materials. ${ }^{25,32}$

Therefore, the $\mathrm{N}_{2} / \mathrm{CO}_{2}$ selectivity of TNPs has been calculated from the isotherms recorded at $273 \mathrm{~K}$ and $298 \mathrm{~K}$ in the pressure
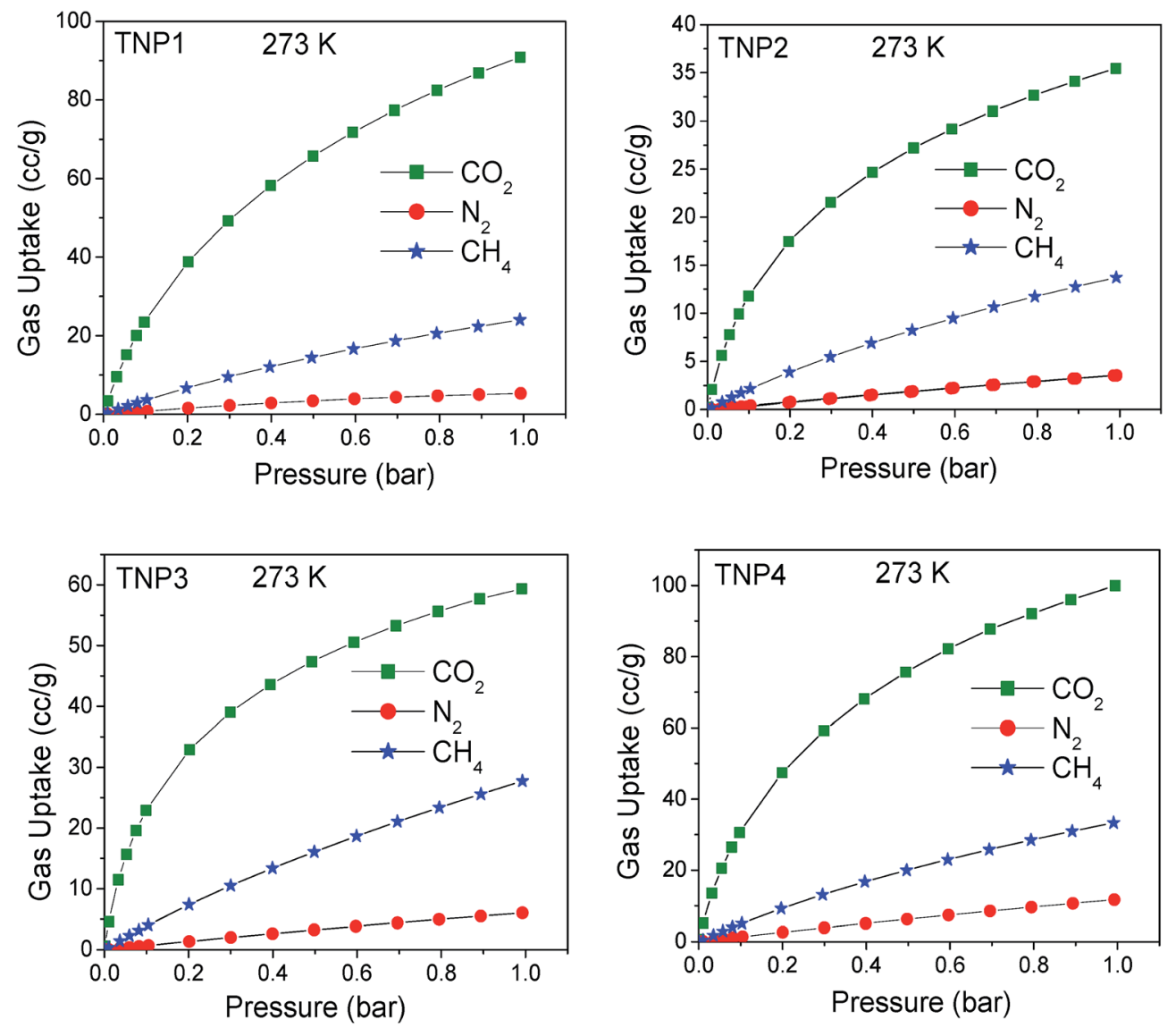

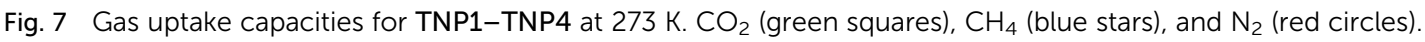


range below 0.15 bar, and the results are summarized in Table 2. Overall, the selectivity at $273 \mathrm{~K}(31-48)$ is higher than the selectivity at $298 \mathrm{~K}(23-31)$ for all TNPs. Amongst these four network polymers, TNP3 shows the highest selectivity for $\mathrm{CO}_{2}$ over $\mathrm{N}_{2}$ (48 at $273 \mathrm{~K}$ ). This may be attributed to the presence of additional pyrazine motifs in TNP3 that are absent in the other three TNPs. This polymer (TNP3) offers more nitrogen sites for interaction with $\mathrm{CO}_{2}$ in comparison to the other TNPs. The data also suggest a considerable trade-off between gas storage capacity and gas selectivity amongst the four TNPs reported herein. For example, TNP4 having the highest surface area $\left(\mathrm{SA}_{\mathrm{BET}}=1348 \mathrm{~m}^{2} \mathrm{~g}^{-1}\right)$ exhibits less selectivity for $\mathrm{CO}_{2}$ over $\mathrm{N}_{2}$ (31 at $273 \mathrm{~K})$ in comparison to TNP1 $\left(\mathrm{SA}_{\mathrm{BET}}=1090 \mathrm{~m}^{2} \mathrm{~g}^{-1}\right.$, $\mathrm{CO}_{2} / \mathrm{N}_{2}=36$ at $\left.273 \mathrm{~K}\right)$ and TNP2 $\left(\mathrm{SA}_{\mathrm{BET}}=460 \mathrm{~m}^{2} \mathrm{~g}^{-1}, \mathrm{CO}_{2} / \mathrm{N}_{2}=\right.$ 40 at $273 \mathrm{~K}$ ). In general, the TNP with a relatively higher surface area exhibits relatively lower $\mathrm{CO}_{2} / \mathrm{N}_{2}$ selectivity. TNP3 is an exception since it has higher nitrogen content than other TNPs. Thus our results corroborate with the general perception that a higher porosity level is accompanied by a compromise in $\mathrm{CO}_{2} / \mathrm{N}_{2}$ selectivity. ${ }^{25,32}$ Nevertheless, the $\mathrm{CO}_{2} / \mathrm{N}_{2}$ selectivities of these 1,2,3-triazole linked network polymers (TNPs) are better than those of a wide range of microporous materials reported in the literature. ${ }^{32,35-38,41,70}$

Additionally, the $\mathrm{CO}_{2} / \mathrm{CH}_{4}$ selectivity of TNPs was also investigated to ascertain their applicability in the purification of natural gas $\left(\mathrm{CH}_{4} / \mathrm{CO}_{2}\right.$ : $\left.95: 5\right)$ by capture of $\mathrm{CO}_{2}$. Methane adsorption isotherms were collected at $273 \mathrm{~K}$ and $298 \mathrm{~K}$ and the selectivity was determined using the initial slope calculation, and the results obtained are depicted in Table 2. $\mathrm{CO}_{2} / \mathrm{CH}_{4}$ selectivities at $273 \mathrm{~K}$ and 1 bar are in the range of $8-9$. At a higher temperature (298 K), the $\mathrm{CO}_{2} / \mathrm{CH}_{4}$ selectivity was found to decrease to 5-6. In general, the TNPs exhibit significantly lower $\mathrm{CO}_{2} / \mathrm{CH}_{4}$ selectivity relative to $\mathrm{CO}_{2} / \mathrm{N}_{2}$ selectivity. It is reported that due to the higher polarizability of methane relative to $\mathrm{N}_{2}$, the adsorption potential of methane is much higher than that of $\mathrm{N}_{2}$ and this may be the explanation for the observed lower $\mathrm{CO}_{2} / \mathrm{CH}_{4}$ selectivities in comparison to $\mathrm{CO}_{2} / \mathrm{N}_{2}$ selectivities. $^{32}$

\section{Conclusions}

In conclusion, facile synthesis and characterization of a series of triptycene based and 1,2,3-triazole laced alternating copolymers has been described. The resulting 1,2,3-triazole linked network polymers (TNPs) are microporous materials exhibiting BET surface area up to $1348 \mathrm{~m}^{2} \mathrm{~g}^{-1}$. We have also shown that incorporation of nitrogen-rich pyrazine moieties results in enhancement of $\mathrm{CO}_{2} / \mathrm{N}_{2}$ gas selectivity relative to TNPs that do not possess this hetero-aromatic structural motif in the polymer backbone. In general, we have shown that integration of triptycene and 1,2,3-triazole motifs in the backbone of organic network polymers results in the yield of materials that demonstrate excellent performance in the storage of small gases at low pressure. Considering the microporosity, large gas uptake and high selectivities of $\mathrm{CO}_{2}$ over $\mathrm{N}_{2}$ and $\mathrm{CH}_{4}$, TNPs are potential candidates for practical applications such as $\mathrm{CO}_{2}$ capture as well as purification of flue and natural gas. Currently, we are extending our research in the direction of a facile synthesis of novel microporous organic polymers with applications in the clean energy sector by utilizing new multifunctional monomers for tailoring the gas sorption properties.

\section{Acknowledgements}

N. D. thanks the CSIR, Govt of India, New Delhi [CSIR No. 02(0126)/13/EMR-II] for financial support. S. M. thanks UGC, New Delhi for a Research Fellowship. The authors acknowledge the Indian Institute of Technology Patna for providing the infrastructure required for this research. The authors also acknowledge Central NMR Facility, CSIR-NCL for acquiring ${ }^{13} \mathrm{C}$ CP-MAS data.

\section{References}

1 K. Sumida, D. L. Rogow, J. A. Mason, T. M. McDonald, E. D. Bloch, Z. R. Herm, T. Bae and J. R. Long, Chem. Rev., 2012, 112, 724-781.

2 B. Chen, S. Xiang and G. Qian, Acc. Chem. Res., 2010, 43, 1115-1124.

3 J.-R. Li, Y.-G. Ma, M. C. McCarthy, J. Sculley, J.-M. Yu, H.-K. Jeong, P. B. Balbuena and H.-C. Zhou, Coord. Chem. Rev., 2011, 255, 1791-1823.

4 W. Zhou, Chem. Rec., 2010, 10, 200-204.

5 Z. Zhang, Z.-Z. Yao, S. Xiang and B. Chen, Energy Environ. Sci., 2014, 7, 2868-2899.

6 W. Shen and W. Fan, J. Mater. Chem. A, 2013, 1, 999-1013.

7 T. A. Makal, J.-R. Li, W. Lu and H.-C. Zhou, Chem. Soc. Rev., 2012, 41, 7761-7779.

8 Z. Xiang and D. Cao, J. Mater. Chem. A, 2013, 1, 2691-2718.

9 S.-Y. Ding and W. Wang, Chem. Soc. Rev., 2013, 42, 548-568.

10 K. Sakaushi and M. Antonietti, Acc. Chem. Res., 2015, 48, 1591-1600.

11 M. L. Foo, R. Matsuda and S. Kitagawa, Chem. Mater., 2014, 26, 310-322.

12 (a) Y. Xu, S. Jin, H. Xu, A. Nagai and D. Jiang, Chem. Soc. Rev., 2013, 42, 8012-8031; (b) X. Feng, X. Dinga and D. Jiang, Chem. Soc. Rev., 2012, 41, 6010-6022.

13 Z. Chang, D.-S. Zhang, Q. Chen and X.-H. Bu, Phys. Chem. Chem. Phys., 2013, 15, 5430-5442.

14 S.-Y. Lee and S.-J. Park, J. Anal. Appl. Pyrolysis, 2014, 106, 147-151.

15 R. Swaidan, M. Al-Saeedi, B. Ghanem, E. Litwiller and I. Pinnau, Macromolecules, 2014, 47, 5104-5114.

16 B. S. Ghanem, R. Swaidan, E. Litwiller and I. Pinnau, Adv. Mater., 2014, 26, 3688-3692.

17 A. Corma, Chem. Rev., 1997, 97, 2373-2419.

18 R. Ryoo, S. H. Joo, M. Kruk and M. Jaroniec, Adv. Mater., 2001, 13, 677-681.

19 F. Hoffmann, M. Cornelius, J. Morell and M. Froeba, Angew. Chem., Int. Ed., 2006, 45, 3216-3251.

20 A. R. Studart, U. T. Gonzenbach, E. Tervoort and L. J. Gauckler, J. Am. Ceram. Soc., 2006, 89, 1771-1789.

21 O. Okay, Prog. Polym. Sci., 2000, 25, 711-779.

22 M. E. Davis and R. F. Lobo, Chem. Mater., 1992, 4, 756-768. 
23 J. Caro, M. Noack, P. Kolsch and R. Schafer, Microporous Mesoporous Mater., 2000, 38, 3-24.

24 Y. Zhu, H. Long and W. Zhang, Chem. Mater., 2013, 25, 16301635.

25 M. G. Rabbani and H. M. El-Kaderi, Chem. Mater., 2012, 24, 1511-1517.

26 W. Lu, D. Yuan, J. Sculley, D. Zhao, R. Krishna and H.-C. Zhou, J. Am. Chem. Soc., 2011, 133, 18126-18129.

27 M. Errahali, G. Gatti, L. Tei, G. Paul, G. A. Rolla, L. Canti, A. Fraccarollo, M. Cossi, A. Comotti, P. Sozzani and L. Marchese, J. Phys. Chem. C, 2014, 118, 28699-28710.

28 M. Saleh, S. B. Baek, H. M. Lee and K. S. Kim, J. Phys. Chem. C, 2015, 119, 5395-5402.

29 J. Wang, I. Senkovska, M. Oschatz, M. R. Lohe, L. Borchardt, A. Heerwig, Q. Liu and S. Kaskel, ACS Appl. Mater. Interfaces, 2013, 5, 3160-3167.

30 V. M. Suresh, S. Bonakala, H. S. Atreya, S. Balasubramanian and T. K. Maji, ACS Appl. Mater. Interfaces, 2014, 6, 46304637.

31 P. Pandey, A. P. Katsoulidis, I. Eryazici, Y. Wu, M. G. Kanatzidis and S. T. Nguyen, Chem. Mater., 2010, 22, 4974-4979.

32 P. Arab, M. G. Rabbani, A. K. Sekizkardes, T. İslamoğlu and H. M. El-Kaderi, Chem. Mater., 2014, 26, 1385-1392.

33 P. Pandey, O. K. Farha, A. M. Spokoyny, C. A. Mirkin, M. G. Kanatzidis, J. T. Hupp and S. T. J. Nguyen, Mater. Chem., 2011, 21, 1700-1703.

34 Y.-S. Bae and R. Q. Snurr, Angew. Chem., Int. Ed., 2011, 50, 11586-11596.

35 Z. Wang, D. Wang, F. Zhang and J. Jin, ACS Macro Lett., 2014, 3, 597-601.

36 H. J. Jo, C. Y. Soo, G. Dong, Y. S. Do, H. H. Wang, M. J. Lee, J. R. Quay, M. K. Murphy and Y. M. Lee, Macromolecules, 2015, 48, 2194-2202.

37 G. Li, B. Zhang, J. Yan and Z. Wang, Macromolecules, 2014, 47, 6664-6670.

38 X. Zhang, J. Lu and J. Zhang, Chem. Mater., 2014, 26, 40234029.

39 Y.-Q. Shi, J. Zhu, X.-Q. Liu, J.-C. Geng and L.-B. Sun, ACS Appl. Mater. Interfaces, 2014, 6, 20340-20349.

40 P. Puthiaraj, S.-M. Cho, Y.-R. Lee and W.-S. Ahn, J. Mater. Chem. A, 2015, 3, 6792-6797.

41 Y. Zhuang, J. G. Seong, Y. S. Do, H. J. Jo, Z. Cui, J. Lee, Y. M. Lee and M. D. Guiver, Macromolecules, 2014, 47, 3254-3262.

42 A. K. Sekizkardes, S. Altarawneh, Z. Kahveci, T. İslamoğlu and H. M. El-Kaderi, Macromolecules, 2014, 47, 8328-8334.

43 M. Salehab and K. S. Kim, RSC Adv., 2015, 5, 41745-41750.

44 B. Ashourirad, A. K. Sekizkardes, S. Altarawneh and H. M. El-Kaderi, Chem. Mater., 2015, 27, 1349-1358.

45 M. Yu, X. Wang, X. Yang, Y. Zhao and J.-X. Jiang, Polym. Chem., 2015, 6, 3217-3223.

46 R. Dawson, E. Stöckel, J. R. Holst, D. J. Adams and A. I. Cooper, Energy Environ. Sci., 2011, 4, 4239-4245.

47 S. Chu, Science, 2009, 325, 1599.

48 R. S. Haszeldine, Science, 2009, 325, 1647-1652.
49 X. Lu, D. Jin, S. Wei, Z. Wang, C. An and W. Guo, J. Mater. Chem. A, 2015, 3, 12118-12132.

50 Y.-S. Bae and R. Q. Snurr, Angew. Chem., Int. Ed., 2011, 50, 11586-11596.

51 H. M. Lee, I. S. Youn, M. Saleh, J. W. Lee and K. S. Kim, Phys. Chem. Chem. Phys., 2015, 17, 10925-10933.

52 C. Zhang, Y. Liu, B. Li, B. Tan, C.-F. Chen, H.-B. Xu and X.-L. Yang, ACS Macro Lett., 2012, 1, 190-193.

53 (a) M. Carta, M. Croad, R. Malpass-Evans, J. C. Jansen, P. Bernardo, G. Clarizia, K. Friess, M. Lanč and N. B. McKeown, Adv. Mater., 2014, 26, 3526-3531; (b) B. S. Ghanem, M. Hashem, K. D. M. Harris, K. J. Msayib, M. Xu, P. M. Budd, N. Chaukura, D. Book, S. Tedds, A. Walton and N. B. McKeown, Macromolecules, 2010, 43, 5287-5294.

54 C. Zhang, T.-L. Zhai, J.-J. Wang, Z. Wang, J.-M. Liu, B. Tan, X.-L. Yang and H.-B. Xu, Polymer, 2014, 55, 3642-3647.

55 T. M. Swager, Acc. Chem. Res., 2008, 41, 1181-1189.

56 Y. He, X. Zhu, Y. Li, C. Peng, J. Hu and H. Liu, Microporous Mesoporous Mater., 2015, 214, 181-187.

57 Q. Wen, T.-Y. Zhou, Q.-L. Zhao, J. Fu, Z. Ma and X. Zhao, Macromol. Rapid Commun., 2015, 36, 413-418.

58 X. Zhu, C.-L. Do-Thanh, C. R. Murdock, K. M. Nelson, C. Tian, S. Brown, S. M. Mahurin, D. M. Jenkins, J. Hu, B. Zhao, H. Liu and S. Dai, ACS Macro Lett., 2013, 2, 660663.

59 S. Chakraborty, S. Mondal, R. Kumari, S. Bhowmick, P. Das and N. Das, Beilstein J. Org. Chem., 2014, 10, 1290-1298.

60 (a) M. I. Mangione, R. A. Spanevello, A. Rumbero, D. Heredia, G. Marzari, L. Fernandez, L. Otero and F. Fungo, Macromolecules, 2013, 46, 4754-4763; (b) S. Chakraborty, S. Mondal and N. Das, Inorg. Chim. Acta, 2014, 413, 214-220; (c) S. Bhowmick, S. Chakraborty, A. Das, P. R. Rajamohanan and N. Das, Inorg. Chem., 2015, 54, 2543-2550; (d) S. Yuan, B. Dorney, D. White, S. Kirklin, P. Zapol, L. Yu and D.-J. Liu, Chem. Commun., 2010, 46, 4547-4549.

61 A. Qin, J. W. Y. Lam and B. Z. Tang, Macromolecules, 2010, 43, 8693-8702.

62 Y. Chen and Z. Guan, J. Am. Chem. Soc., 2010, 132, 45774579.

63 K. S. W. Sing, Pure Appl. Chem., 1982, 54, 2201-2218.

64 P. Mohanty, L. D. Kull and K. Landskron, Nat. Commun., 2011, 2, 1-6.

65 M. G. Rabbani and H. M. El-Kaderi, Chem. Mater., 2011, 23, 1650-1653.

66 M. G. Rabbani, T. E. Reich, R. M. Kassab, K. T. Jackson and H. M. El-Kaderi, Chem. Commun., 2012, 48, 1141-1143.

67 A. P. Katsoulidis and M. G. Kanatzidis, Chem. Mater., 2011, 23, 1818-1824.

68 R. Vaidhyanathan, S. S. Iremonger, K. W. Dawson and G. K. H. Shimizu, Chem. Commun., 2009, 45, 5230-5232.

69 J. An, S. J. Geib and N. L. Rosi, J. Am. Chem. Soc., 2010, 132, 38-39.

70 W.-C. Song, X.-K. Xu, Q. Chen, Z.-Z. Zhuang and X.-H. Bu, Polym. Chem., 2013, 4, 4690-4696. 